\title{
The Concept of China's Light Industry Development by Means of Industry Clusters Creation and Digital Technologies
}

\author{
Zhen Yuan \\ Saint-Petersburg State University of Industrial Technologies \\ and Design \\ Saint Petersburg, Russia \\ Pavel Alekseevich Shikov \\ Saint-Petersburg State University of Industrial Technologies \\ and Design \\ Saint Petersburg, Russia \\ pavel.shikov@mail.ru
}

\begin{abstract}
The article discusses the development prospects of China's light industry by forming strategic economic zones using textile enterprises as an example. SEZ are based on the concept of successful digital economy development by strengthening vertically and horizontally oriented industrial structures. The state of light industry enterprises is determined, which most closely corresponds to the needs of the market in the volume and range of products, taking into account the global distribution of labor. A search is made for that kind of areas of digital economy development that would ensure the continuous development of China's light industry. The scope and depth of systemic problems in China's light industry are investigated. The importance of light industry for the national economy of China, the importance of the digital economy, the need to use adequate methods and mechanisms for the industry development, which can provide a sustainable competitive advantage for light industry enterprises for many years, are determined.
\end{abstract}

Keywords: industry cluster, strategic economic zone, light industry, digital economy

\section{INTRODUCTION}

Exhaustion of the possibilities for the development of the world economy within the framework of the concept of globalism in its current form predetermines the transition of the world economy to a new model. A distinctive feature of this model is the protection of national interests, primarily the national producer. In the framework of this concept, each country will be forced to formulate its economic and industrial policy based on the preservation of jobs and attracting business, which is designed not only to saturate the domestic market, but also to minimize unemployment, on the one hand,

\author{
Ludmila Nikolaevna Nikitina \\ Saint-Petersburg State University of Industrial Technologies \\ and Design \\ Saint Petersburg, Russia \\ Yuriy Alekseevich Shikov \\ Saint-Petersburg State University of Industrial Technologies \\ and Design \\ Saint Petersburg, Russia
}

and, on the other, to boost the export of products for which the country has a competitive advantage. The most important success factor is the use of the principles of the digital economy. From this point of view, light industry is a very attractive sector of economic activity, as it is the crucial multidisciplinary sector of the economy [1]. The activities of light industry enterprises are based on several concepts:

- products of light industry enterprises are durable goods;

- the use of consumer goods is seasonal;

- light industry goods are subject to moral rather than physical deterioration, which determines the need for fast updating of the range of products;

- the end user agrees to pay a higher price for the fame of the manufacturer of the goods, which should indicate a high quality product;

- the end user is interested in the uniqueness of the product, which reduces serial production and requires a greater variety of products;

- production of light industry products is large-scale;

- during the transition from one series to another, as a rule, production updating or modernization is not required;

- the share of equipment costs in the prime cost of products decreases for a unit of production from natural fibers due to rise in prices for raw materials, 
and decreases for products made of artificial fibers due to outstripping growth in prices for equipment.

For the national economy of China, the development of light industry is a guide within the framework of the fourth industrial revolution (Industry 4.0) [2], which significantly transforms the industry:

- helps to increase the employment of the economically active population, since the products of this industry are labor-intensive;

- directly meets the needs of the population and contributes to the development of production of industrial goods, as it produces the necessary components for these goods;

- stimulates the growth of consumption and production output;

- contributes to economic growth, which allows to quickly increase national income and exports;

- ensures the fullness of the budget, which contributes to the social stability of society.

For businesses, this industrial sector:

- is highly profitable and pays off quickly;

- is attractive in the field of innovative development;

- can be placed on any territory, since there are no significant restrictions on energy resources and transport accessibility;

- despite intense competition, this market is characterized by the existence certain niches that provide relatively comfortable access to the market;

- should always have the support of legislative and executive territorial authorities interested in the growth of employment rate.

The potential of the country's digital economy should and will be strengthened by powerful industry and corporate structures. First of all, these are strategic economic zones and industry clusters. "The successful development of the digital economy will be ensured by strengthening the position of corporations, increasing the quality of corporate governance principles, and increasing the interaction and clarity of the relevant structure of financial institutions. These changes are much more serious than the initial changes in the field of information and communication technologies (ICT) which contributed to the development of the digital economy. Changes have taken place in every sector of the market: competitive structures, consumer preferences, purchasing habits, marketing and advertising» [3].

Most of the light industry market, tied to the solvency and preferences of the individual consumer, focuses on the availability of goods, their quality and design, as well as presale services and advertising.

From the point of view of the efficiency of light industry, it is important to maintain the share of consumer goods in the volume of output [4]. Light industry is an attractive part of the durable goods market from such points of view as purely financial, creating new jobs, and developing small and medium-sized businesses. A very significant problem for light industry is the shadow economy (illegal imports and unaccounted for (underground) production, the volume of which, as exemplified by Russia, more than doubles the level of legal production and imports and reaches $43 \%$ [4]).

Attempts to compete with the shadow economy and smuggled products are forcing legitimate producers to lower prices due to the deterioration of product quality. The influence of the shadow economy affects the decrease in demand, decrease in profits and tax deductions to the budgets of all levels of government, decrease in employment rate and solvency of potential consumers.

Therefore, the protection of national interests is realized in the desire to develop the domestic market by supporting the national producers, regulating imports in its interests by supplementing the national market with the necessary assortment groups of high-quality goods, and establishing fair competition. Access to the national market and foreign manufacturers is necessary in order to avoid monopolism, the consequence of which may be such negative consequences as overpricing, inferior quality.

A serious problem for the industry is timely modernisation with new equipment, updating technology and organizing production through digitalization and automation at the expense of enterprises own and borrowed funds. In developed countries, the average equipment update rate is $15-17 \%$ per year, i.e. the depreciation period of equipment is much less than 10 years [5], [6], [7]. In developing countries, for example, in Russia, the equipment renewal rate is $3-4 \%$ per year. The low level of equipment upgrade affects the reduction of production capacity. On the other hand, updating equipment contributes to the development of domestic engineering, thereby also contributing to an increase in the rate of economic development of the country. The aim of the update is to reduce costs, increase the profitability and competitiveness of industry enterprises. This policy should be closely connected with the investment policy of the state, the purpose of which is the development of light industry. The obsolescence of the production and technological base of light industry enterprises leads to a decrease in sales, and hence output volumes, and, as a result, a loss of market share. In addition, such a technical policy reflects a lag in the level of organization of production, poor management in the management of enterprises, the ineffective work of their marketing services, none of the effectiveness of personnel policies, leading to a loss of staff competencies, and increased turnover.

The lack of dynamic development of light industry leads to negative consequences in other sectors, such as agriculture, mechanical engineering, and the chemical industry (production of raw materials, dyes, textile auxiliary substances). The lag in the development of light industry leads to an increase in costs due to an increase in energy costs for the operation of obsolete equipment. As a result, there has been a growth in imports of products not only of light industry, but also of other interconnected industries. 


\section{MATERIALS AND METHODS}

The low level of innovation and investment activity in light industry compared to leading countries may be due to:

- lack of necessary investments for modernization of light industry enterprises on the basis of new "breakthrough" innovative technologies relating to both management and production;

- reducing the amount of scientific research funding, leading to a decrease in the effectiveness of research and development, as well as the loss of scientists who are able to generate innovations. Scientific developments contribute to the creation of a new technological basis that stimulates the expansion of the production of competitive high-tech products.

- low level of the results of scientific research use, which is negatively reflected in costs, profitability, output and the rate of updating the range of products.

The technological lag of light industry leads to the development of the shadow economy due to:

- mismatch of the assortment, quality and volume of production to demand both on the national and foreign markets;

- insufficient development of the fashion industry, which is lagging behind global trends;

- low wages with high labor intensity;

- exorbitant legal requirements for workplaces equipment and accreditation.

Given the scale and depth of the systemic problems of light industry, its importance for the national economy of China, the importance of economy digitalization, it is crucial to use adequate methods and mechanisms for solving them:

- improving the legislative framework in the field of production, trade, export and import, tariff-customs and tax regulation, interaction of light industry sectors with suppliers of raw materials and equipment;

- support by state institutions during the technical reequipment and modernization of production;

- support for the development of both industry science and its scientific and experimental base, as well as the implementation of projects for the industry enterprises development;

- legislative protection of domestic producers from smuggling and counterfeit products, creating conditions for the effective functioning of a civilized consumer goods market and the development of its infrastructure;

- timely improvement of customs and tariff legislation that would expand trade and economic cooperation while specifying the list of countries that use tariff preferences unilaterally.
The problem of employment of the population and replenishment of the budget makes most countries pay special attention to the development of light industry, the provision of substantial investment support and the provision of tax benefits. Therefore, there is a constant improvement of the legislation ensuring the effective interaction of executive authorities with business and financial structures, with the aim of developing small and medium-sized businesses, including light industry.

To improve the system of achieving goals in the industry, it is necessary to focus on not just short-term but mainly on long-term tasks.

The first task, which touches upon the solution of the problems of the light industry development on the basis of the widespread introduction of digital technologies, is to determine the list of promising strategic economic zones and industrial clusters [8], forecast their capacities, and also the possible share that the enterprise is counting on. A strategic business area is a separate market segment, characterized by the uniformity of consumer demands in terms of specific products on which the company sells or intends to sell its products.

The second task, determining the development of light industry, is to ascertain the vision of enterprises, i.e. such a state of the enterprise that most closely matches the needs of the market in the volume and range of output of its products in accordance with projected demand. Moreover, in accordance with the concept of the transition from narrow specialization to vertical integration along the value chain of the products proposed for release to the enterprise, several business units can be included, with each specializing in one of the operations. The results of these operations should ensure the execution of subsequent operations of the value chain.

The third task is to determine an investment and innovation policy that will ensure the evolutionary transformation of the enterprise architecture in accordance with the vision from the current state based on minimizing attracted investments.

According to our assessment, the dynamics of China's light industry and its main component, the textile industry, are practically consistent with the dynamics of GDP and industrial production. Without the digitalization of all areas of the industry, significant improvement cannot be achieved. «Digital economy represents (a) a system of production relations (in the narrow meaning) in the distribution of resources during the production and data transfer though Information and Communication Technologies (ICT), (b) a system of economic agents that create added value by selling their services of production and data transfer through ICT. Whether such economic agents should constitute the digital economy is the matter of analyzing their value creation chains. They do, if they create added value with digital means of production» [9].

Currently, the main trends in the development of light industry include: 
- increased use of intelligent digital technologies for functional clothes, shoes, accessories, for example, for measuring body functions;

- improving working conditions and the use of resourcesaving technologies, including environmental and ethical components;

- stimulation by the legislative and executive authorities of the development of light industry enterprises, improvement of product quality, production of natural materials, such as silk and cotton.

Production growth rates are maintained by attracting largescale investments, vertical and horizontal integration of production, creating modern joint ventures with a high level of digitalization and automation of production. The efforts of the legislative and executive authorities of each country and region are aimed at creating the conditions for the effective development of their producers and the implementation of targeted government policies.

\section{RESULTS}

The accelerated development and use of scientific potential ensure the dynamic growth of light industry through modernization and technical re-equipment, optimization of the industry potential and the necessary structural transformations. These events define a new stage in the development of light industry, characterized by a constant increase in innovation investments, updating the product line and technology, and the opening of new markets.

Recently, the light industry has undergone significant transformations, including:

- global displacement of production centers;

- structural changes in sales markets;

- changing the industry management philosophy.

That kind of light industry transformations were caused by a number of reasons:

- structural changes in the economies of producing countries due to the transfer of production to countries with low labor costs;

- an increase in the share of fixed capital in the assets of enterprises associated with an increase in the level of technological development;

- adoption of WTO standards to regulate the industry with the subsequent abolition of quotas [10];

- periodic fluctuations in consumer activity in connection with the crisis in the economy;

- growing consumer demands for quality, durability and design for the entire spectrum of light industry products;

- prompt updating of the assortment ("fast fashion").

The emerging situation stimulates the formation of synthesized industrial clusters, allowing to expand the 
liberalization and the abolition of import quotas in a number of countries. Therefore, even the customs and tariff barriers that have been preserved in some places could not restrain the expansion of developing countries.

Studies show that in this case the following features of light industry were important:

- the constant presence of light industry enterprises in each country; therefore, the creation and expansion of such production is not a fundamentally new thing for local business;

- low entry barriers to light industries;

- relatively simple and flexible manufacturing process;

- low employment rate in developing countries, which implies ample opportunities for its attraction to light industry enterprises and low wages;

- synergies due to positive external effects leading to an increase in the scale of production and increase the competitiveness of all enterprises in the cluster;

- integration due to synchronization and balanced development of cluster enterprises, as a result of combining operations in value chains of products and eliminating market barriers between cluster members, accompanied by a reduction in transaction costs, increased profitability and competitiveness;

- accelerate innovation by concentrating $\mathrm{R} \& \mathrm{D}$ with a concomitant reduction in the time and costs of creating and introducing new products and the technologies and necessary equipment;

- synchronization of investments designed to better cover the value chain operations of a new product or increase the efficiency of an existing one;

- creating additional demand for raw materials and auxiliary materials, equipment, new technologies and products;

- $\quad$ specialization as a consequence of the need to increase output;

- growth multiplication due to increased interaction between enterprises;

- market expansion as a result of the elimination of competition between cluster members who are forced to develop joint marketing programs and ensure sales growth.

Recently, there has been a shift in light industry production centers to the countries of Southeast Asia, Turkey, Latin America, which currently account for $70 \%$ of world exports of clothing and textiles. Only China accounts for more than $30 \%$ of total world exports. Although the level of consumption in the USA, Germany, France and Japan exceeds $50 \%$ of the global consumption of clothing and textiles [11], these countries, previously considered leaders in this field, have taken the role of importers of light industry products. The restructuring of the markets was the result of the extension of WTO procedures to world trade relations, their subsequent
- short period of staff training due to lower requirements for their qualifications.

Light industry is becoming more and more high-tech [12], which causes the need to develop and introduce innovative products and technologies to strengthen competitiveness. This trend is determined both by the possibilities of the production volume increase by the agro-industrial complex, and by innovations in the chemical industry. Therefore, production volumes growth, changes in its structure and updating the assortment of light industry directly depends on the development of the above industries. Modern scientific developments stimulate the introduction of digital and information technologies in the production process, new technological processes [13], [14], including:

- automation of the design and production process;

- methods of dyeing raw materials;

- final processing of tissues methods,

- digital color matching methods.

The increase in the science intensity of light industry is the result of intense competition in international markets due to the internationalization of production. In turn, internationalization is accompanied by a massive shift in production capacity to countries with cheaper labor. The countries of Western Europe (in particular, Germany, Italy, France) first moved production to the countries of Eastern Europe (Hungary, Czech Republic). Further, these countries began to locate production in:

- Asia (China, India, Thailand, Vietnam, Pakistan, Uzbekistan);

- Eastern Europe (Lithuania, Belarus)

- Latin America.

The internationalization of production in light industry is also carried out through the creation of joint ventures, through the implementation of joint projects, the experience and information exchange, the pooling of investments and resources, especially in the scientific and technical field. 


\section{Light industry}
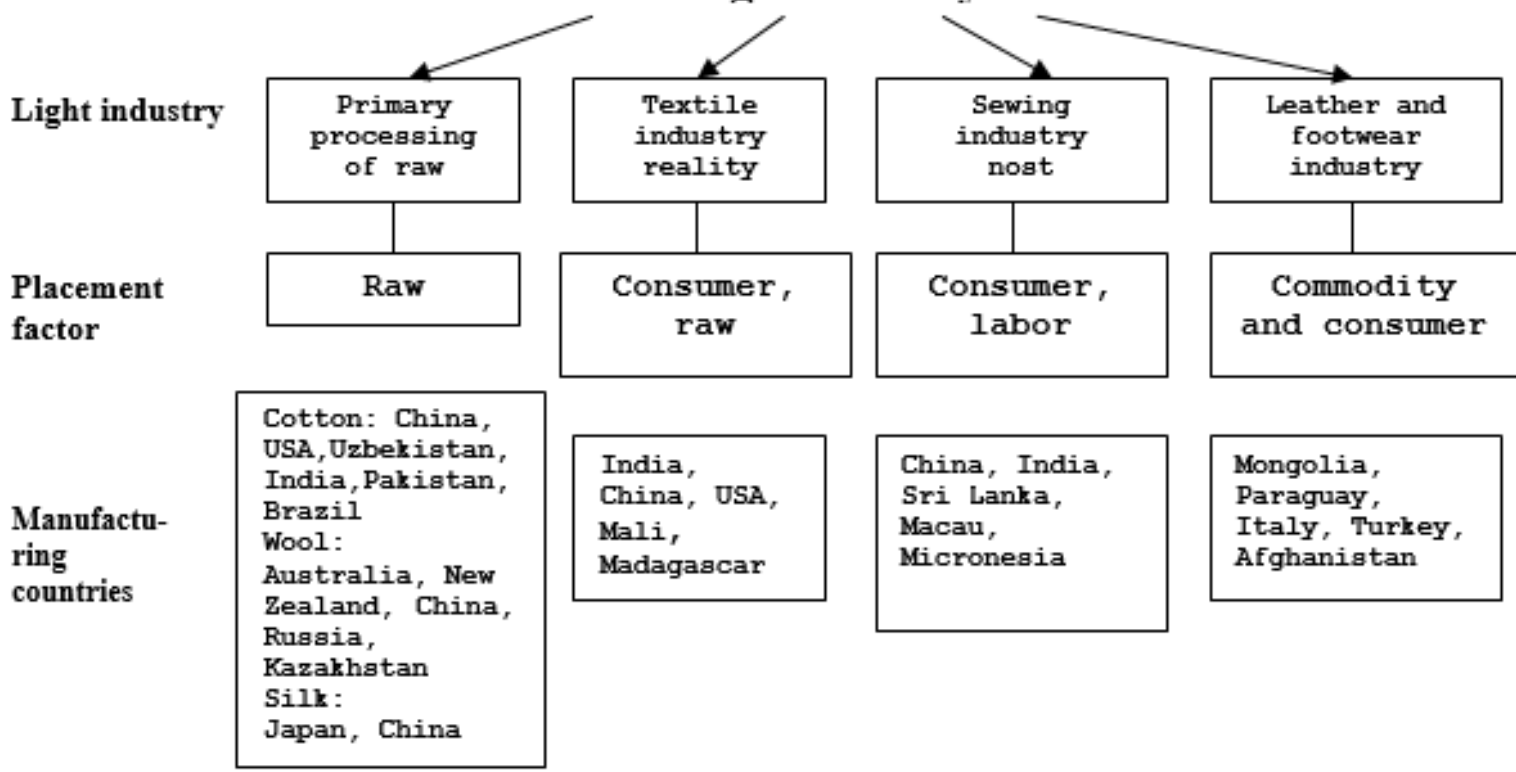

Fig. 1. Light industry structure (raw materials and placement)

This trend is expressed in the consolidation of the design and mass production of fashion products by European manufacturers, by:

- presentation of designer collections on the catwalks and sales to buyers for advertising purposes;

- $\quad$ subsequent adaptation of the selected models for mass consumption and the organization of mass production at enterprises.

Such cooperation is mutually beneficial for:

- raw materials manufacturers, which supply raw materials for designers, have all the opportunities to prepare production in order to timely update the range;

- fashion houses (designers), which have the opportunity to reduce their costs by investing in the production of raw materials and final products, as well as by gaining the opportunity to strengthen the advertising impact on consumers, promoting their products in the interests of all three parties;

- manufacturers of final products, which timely update their assortment, focusing on fashionable products in high demand, reduce the risk of new products.

Due to this strategy behavior, producers also benefit endusers by expanding choice and affordable prices. Thus, the coordination of product design and industrial production operations in a continuous value chain is a very promising direction in the development of light industry. For all participants, the development of such cooperation allows us to move from the concept of obtaining benefits from narrow specialization to the concept of minimizing costs along the entire value chain of products.
World Economic Crisis 2008-2009 and the subsequent recession significantly affected the development trends of light industry, which manifested itself in a decrease in the growth rate of the industry and an increase in production costs. The structure of light industry in terms of raw materials and territorial distribution is shown in Figure 1. However, light industry is a sector that is quite resistant to global economic shocks, and following a market decline of $0.7 \%$ in 2008 , an increase of $4 \%$ in 2010 was followed. the growth rate of the global light industry market is about $6 \%$ per year.

The pattern of changes in the sectoral structure of the world economy can be traced in a gradual transition from the predominance of agriculture and the mining industry to the dominance of manufacturing industries with relatively simple production technologies (light, food industries), and then from capital - and material-intensive industries to knowledge-based industries based on high technology and digital economy. The ratio between the above sectors is constantly changing in favor of the latter in terms of their contribution to the gross domestic product (GDP) and the share of the employed population. In recent decades, the developed countries are characterized by the onset of deindustrialization and the formation of a postindustrial society with a sharp increase in the value of the knowledge economy, including the financial sector, computer science, education, science, medicine, communications, telecommunications, transportation, and trade.

National economies are so closely intertwined in the modern globalized world that their mutual influence and development determine the vector of the future development of each country. Currently, there is a slowdown in economic growth in many countries amid the instability of their economies. Large-scale economic policies adopted by governments have helped stabilize financial markets. But as the budget deficit and public debt grew, these measures ceased 


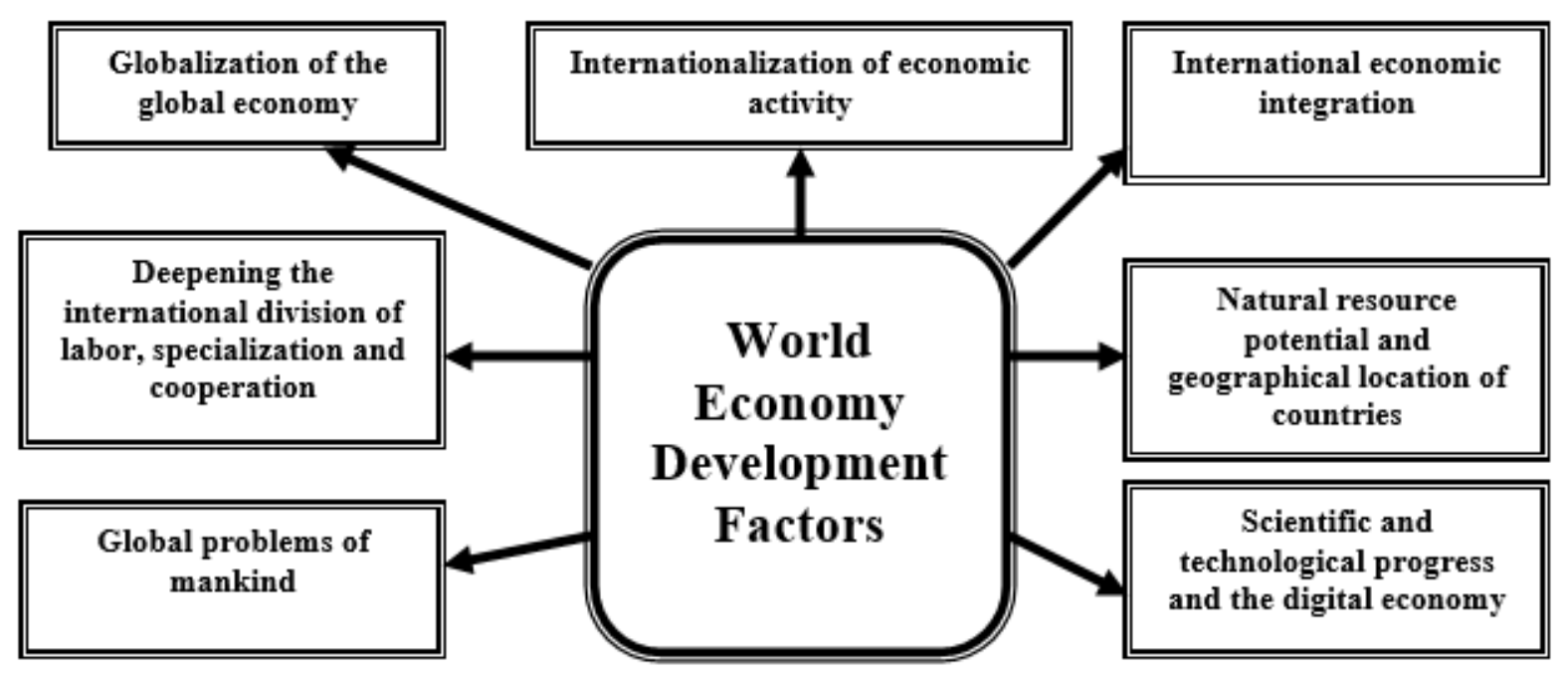

Fig. 2. Factors determining the development of the global economy

to have a positive effect. Therefore, governments are forced to change to resort to austerity of budgetary funds, which negatively affects the growth of the global economy. It is a positive advance that developing countries continue to maintain high growth rates (especially China and India), while continuing to be the driving force behind the global economic recovery.

The dynamics of structural changes in the economic structure determines the trends in the development of the economy, which affects the proportion in the production and consumption of the gross product and, therefore, is of great importance for the sustainable and efficient development, distribution of investments and government spending.

Structural shifts can be interpreted in a narrow and broad sense. In a narrow sense, structural shifts represent changes in the assortment and output of enterprises in the industry. For example, during the period of economic crises, the proportion of expensive products increases due to a decrease in the output of cheap goods. In a broad sense, structural shifts lead to changes:

- in the use of production facilities;

- in the volume of consumption of material and energy resources:

- in size and direction of investments;

- in the use of information technology;

- in the rate of renewal of fixed capital;

- as part of the workforce (gender and age, professional, qualification structure).

Structural changes in the world economy are ongoing and uneven. So, from the second half of the 20th century, two periods can be distinguished:

1. $1950-1975$ years. high rates of economic growth of developed countries amid structural shifts in various sectors of the economy (agriculture, industry) in favor of developing the service sector.

2. 1975 - 2000 the manifestation of structural shifts at the intra-industry level by increasing the scale of production against the background of using the achievements of scientific and technological progress (for example, automation and digitalization) and changing forms of organization of production.

Currently, the global economy forms a single space in which the actors are, first of all, transnational corporations and their alliances, international organizations, states and their regional associations, as well as global associations that together form the global community. In its composition, the economy is characterized by heterogeneity in terms of the level of development of productive forces achieved by the subjects, the nature, scale and forms of economic relations. All subjects are interconnected through a system of economic relations, which are recorded in international and national legal and regulatory documents. The world economy is affected by countless factors reflecting the dynamism and inconsistency of economic relations (Figure 2).

This leads to uneven development, structural changes in the economy, i.e. changes in the share of the industry in GDP. Structural changes can be associated with the seasonality of consumption of certain products or services. But structural changes can be manifested in the form of patterns, reflecting not only the volume of output, capacity utilization, but also long-term changes in the fixed capital and investments of the industry. The immediate causes of structural shifts include the pace of digital technology adoption, as well as changes in the solvency and living standards of the consumer or the structure of their preferences and expenses, which are associated with:

- inflationary or deflationary processes that cause massive unidirectional price changes;

- economic crises, reduced business activity, leading to lower costs to consumers; 
China is the second after the United States in terms of the total value of the services sector, but per capita income remains below the global average. In terms of economic growth, China is in a leading position.

In China, the leading industries include light industry, which accounts for more than $21 \%$ of all industrial production. The enterprises of these industries are located mainly in the Eastern, Northern, Central-Southern regions. Only enterprises of the textile industry, there are more than 23.3 thousand. The production and processing of raw materials for these enterprises is clearly oriented: in the North - wool, hemp, in the South - silk, jute, kenaf [15]

China has abandoned central planning in favor of a more market-oriented system. Reforms in China were carried out evolutionarily, starting with agriculture, and affected all aspects of the economy. The most important trend in modern China is the digital economy.

The main directions of reforming the Chinese economy were:

- gradual price liberalization;

- financial decentralization;

- increasing the independence of state enterprises;

- creating a diverse banking system;

- development of stock markets;

- the rapid growth of the private sector;

- increasing the openness of the economy;

- expansion of foreign trade;

- attracting foreign investment.

Thus, the development process is accompanied by both positive and negative phenomena in the architecture of the economy, which leads to the need for structural changes. To foster structural change, China has prioritized the introduction of digital technology and the development of leading industries.

The main result of the research is recommendations for the further development of China's light industry in the form of synthesized industrial clusters. This conclusion is based on the dynamics of real economic processes, when at every moment in time the architecture of the economy of each country is a necessary complement to the global economy, thereby ensuring economic balance through foreign trade, redistribution of capital and population transfer between countries and regions. Imbalance leads to a change in the price structure and contributes to a change in output in sectors and sectors of the economy.

\section{References} Surpassing Japan in 2001, China over the past few years has been number one in the world in terms of this indicator.

According to the IMF and World Bank, the value of China's agricultural and industrial production in dollar terms exceeds the similar indicators in the United States since 2014.
[1] S. Motuz, L. Nikitina, and Z. Yuan, "Upon the issue about the textile and clothing industry development in PRC", International Journal of Applied Engineering Research, vol. 10, no. 20, pp. 41011-41017, 2015.

[2] U.A. Dmitriev and M.M Omarov, "Increasing the efficiency of light and textile industry through the creation of regional clusters 
[10] Wages and Working Hours in the Textiles, Clothing, Leather and Footwear Industries: Issues Paper for discussion at the Global Dialogue Forum on Wages and Working Hours in the Textiles, Clothing, Leather and Footwear Industries - Geneva: International Labour Organization, 2014 [Electronic resource]. Available at http://www.ilo.org/wcmsp5/groups/public/@ed_dialogue/@sector/docu ments /publication/wcms_300463.pdf.

[11] Key problems in the development of light industry in Russia and how to overcome them: analytical report. M.: Higher School of Economics, 344 p., 2013.

[5] Ch. Yuan and L.N. Nikitina, "To the question of the control system in the light industry of the PRC", Economics and Management Systems Management, no. 4.2 (18), pp. 230-234, 2015.

[6] Ch. Yuan and L.N. Nikitina, "The main determinants of China's light industry competitiveness", University proceedings: Technology of light industry, no. 3, pp. 43-47, 2015.

[7] Ch. Yuan and L.N. Nikitina, "On the issue of innovations in the light industry of the PRC", Economics and Management Systems Management, no. 3.1 (17), pp. 141-147, 2015.

[8] Jiang Lan, Wang Chengjun and Zhang Wei, "Investigation of the evaluation system of SMEs' industrial cluster management performance based on wireless network development", EURASIP Journal on Wireless Communications and Networking, 2019. DOI: 10.1186/s13638-018-1318-8.

[9] S.A. Filin and A.Zh. Yakushev, "The organizational and administrative framework for the digital economy”, Digest-finance, no. 3 (251), 2019.

[12] S.E. Yepanchintseva, "State mechanism to ensure enterprise competitiveness in textile and clothing industries: Use of international experience for Kazakhstan", Interdisciplinary Perspectives on Social Newcastle upon Tyne: Cambridge Scholars Publ., pp. 129-136, 2014.

[13] N. Brousek, "Fertigung technischer Textilien und Hochleistungsgewebe mit Profinet und SPS", Melliand Textilber, t. 94, no. 3, pp. 159-160, 2013.

[14] E.T. Ngai, S. Peng, P. Alexander, and K.L. Moon, "Decision support and intelligent systems in the textile and apparel supply chain: An academic review of research articles", Expert Systems with Applications, vol. 41, iss. 1, pp. 81-91, 2014.

[15] China Industry [Electronic resource]. Available at: http://industry.imextrade.ru/education/the-industry-of-china/. 